\title{
On the Formation of Organosulfur Pseudo- Components in the Raw Materials of the Diesel Fuel Hydrotreating Process
}

ISSN: 2637-8035

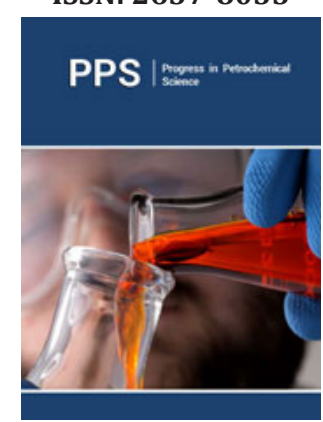

*Corresponding author: Samoilov NA,Department of Petrochemistry and Chemical Technology, Russia

Submission: 罜 October 18, 2020

Published: 侮 December 01, 2020

Volume 3 - Issue 5

How to cite this article: Samoilov NA, Zhilina VA. On the Formation of Organosulfur Pseudo-Components in the Raw Materials of the Diesel Fuel Hydrotreating Process. Progress Petrochem Sci. 3(5). PPS. 000573. 2020. DOI: $10.31031 /$ PPS.2020.03.000573

Copyright@ Samoilov NA, This article is distributed under the terms of the Creative Commons Attribution 4.0 International License, which permits unrestricted use and redistribution provided that the original author and source are credited.
Samoilov $\mathrm{NA}^{1 *}$ and Zhilina $\mathrm{VA}^{1}$

${ }^{1}$ Department of Petrochemistry and Chemical Technology, Russia

Opinion

Mathematical modeling of the diesel fuel Hydrotreating process is impossible without a database on the composition and physical and chemical properties of organosulfur components in the feedstock, since the degree of activity of sulfur compounds in hydrogenolysis reactions is different and decreases in the series: mercaptans $>$ sulfides $>$ thiophenes $>$ benzothiophenes $>$ dibenzothiophenes. There are alternative solutions to the problem of describing the composition of Hydrotreating raw materials.

The first option is to identify the most complete set of organosulfur components of diesel fuel and develop a data Bank of possible reaction routes; this solution, in principle, allows the most adequate characterization of Hydrotreating raw materials, but it is the most time-consuming and not always solved from the point of view of the sensitivity of analytical devices. We can note a generalization of the thermodynamic parameters of hydrogenation reactions (entropy and Gibbs energy) for 38 organosulfur components [1]. However, it is quite problematic to implement kinetic experiments to obtain the physical and chemical characteristics of reactions necessary for modeling the process, first of all, the constants of the Arrhenius equation (activation energy and pre-exponential multiplier) due to the microconcentrations of many components in the reaction mixture.

The second option is to formally combine the components of one group of organosulfur substances into a conditional pseudo-component [2-4], but the calculated constants of both the Arrhenius equation and the reaction rate constants themselves are effective and do not allow forming an objective analysis of the reaction process. For example, in [2], the study of diesel fuel desulfurization was performed using the following conditional pseudocomponents: sulfides, ethylbenzothiophenes, propylbenzothiophenes, butylbenzothiophenes, dibenzothiophenes, methyldibenzothiophenes and ethyldibenzothiophenes, but in [3] a different grouping of pseudo-components was used. In [3] also provides an example of representing the composition of organosulfur components in diesel in the form of 2, 3 and 4 pseudo-components, in the latter case they were divided into very easily hydrogenated, easily hydrogenated, difficult hydrogenate and very difficult to hydrogenate without identifying the hydrogenated components.

In this regard, we propose to conditionally divide the initial diesel fuel into $\mathrm{N}$ narrow fractions, in each of which the set of organosulfur components is considered as a pseudocomponent, for which the rate constant of the hydrogenation reaction can be easily determined experimentally. With this representation of pseudo-components, the results of mathematical modeling will be determined only by the number of narrow fractions. We have performed mathematical modeling of diesel fuel hydrotreatment taking into account from two to 16 pseudo-components. The model of Hydrotreating process kinetics in this case has the form of a system of equations

$$
\frac{d C_{S 1}}{d \tau}=-K_{1} C_{S 1}
$$




$$
\begin{aligned}
& \frac{d C_{S 2}}{d \tau}=-K_{2} C_{S 2} \\
& \frac{d C_{S 3}}{d \tau}=-K_{3} C_{S 3} \\
& \frac{d C_{S N}}{d \tau}=-K_{4} C_{S N}
\end{aligned}
$$

where $\mathrm{C}_{\mathrm{SI}}$ and $\mathrm{K}_{\mathrm{i}}$, respectively, are the concentration of the organosulfur pseudo-component and the rate constant of the i-th reaction.

\section{References}

1. Afanasyeva YI, Krivtsova NI, Ivanchina ED, Zanin IK, Tataurshchikov AA (2012) Development of a kinetic model of the diesel fuel hydrotreating process. Izvestiya Tomsk Polytechnic University 321(3): 121-125.

2. Krivtsova NI, Krivtsov EB, Ivanchina ED, Golovko AK (2013) Kinetic regularities of hydrodesulfurization of diesel fraction. Fundamental Research 8(3): 640-644.

3. Tang X, Li S, Yue C, He J, Hou J (2013) Lumping kinetics of hydrodesulfurization and hydrodenitrogenation of the middle distillate from Chinese shale oil. Oil Shale 30(4): 517-535.

4. Bannatham P, Teeraboonchaikul S, Patirupanon T, Arkardvipart W, Limtrakul S, et al. (2016) Kinetic evaluation for hydrodesulfurization via lumped model in a trickle-bed reactor. Industrial \& Engineering Chemistry Research 55(17): 4878-4886. 